DR VERICA RUPAR is associate professor in journalism at AUT University.

\section{A fresh take on journalism authority}

Citizen Witnessing, Stuart Allan. Cambridge, UK: Polity Press, 2013, 253 pp. ISBN-13; 978-0-7456-5195-8

$\mathrm{T}$ HE implications of the internet for journalism practice have been widely explored in journalism studies scholarship, and interest in new forms of digital journalism practice has outgrown interest in the analysis of traditional forms of news production. It has been some time since journalists lost their exclusive right in deciding what publics see, hear and read. In a digital environment, information is no longer scarce or hard to produce. Having a smart phone easily opens a door to publishing and the potential of new technologies to create a situation where everybody could be a journalist seems endless. Recording events using digital and mobile tools has become a daily routine for an unprecedented number of people who upload text, photographs and videos to the internet. The technological

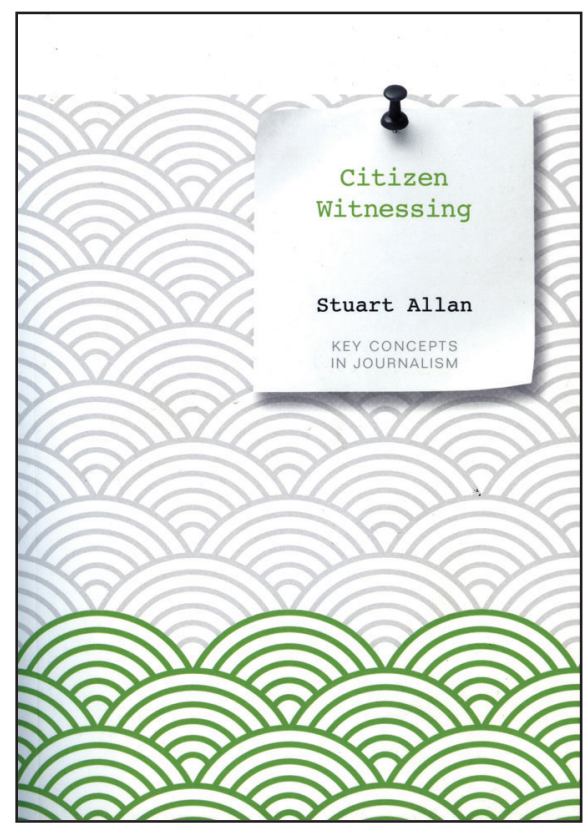

changes have underpinned a paradigmatic shift in journalism: by enabling the public to engage directly in news production it has demonstrated the impossibility for reporters of maintaining the traditional gatekeeper role of journalism.

Citizens' recording of dramatic events-a trigger for Stuart Allan's latest book Citizen Witnessing-offers a fresh angle from which to view journalism. Developing ideas from his previous work on online and citizen journalism, Allan introduces the concept of 'citizen witnessing' as a driving force and a key notion in journalism. Unpacking new forms of production shows that ordinary 
people in extraordinary situations do what journalists do: collect, process and disseminate information by tweeting, blogging and posting texts, images and video recordings.

Allan's operational definition of citizen journalism as 'a type of firstperson reportage in which ordinary individuals temporarily adopt the role of a journalist in order to participate in news-making, often spontaneously during a time of crises, accident, tragedy or disaster when they happen to be present on the scene' (p.9) outlines citizens' willingness and capacity to take back journalists' delegated authority in recording, producing and sharing information. Going beyond the current debate about the importance of making a distinction between amateurs and professionals-coloured sometimes in terms of professional expertise or the place of journalism within the wider structure of power-he looks at journalism as a public service and, using an outstanding range of examples, argues that the digital and mobile tools in the hands of millions of citizens carry the potential to significantly contribute to the democratisation of public life.

Being on the ground and being a witness, Allan argues, has been an intrinsic element of journalism for a long time. One does not have to look only to mainstream journalism to realise that the authority of professional journalists has been historically twofold: being a reliable witness and being a mediator of other eyewitnesses accounts.

In Citizen Witnessing this authority of presence has been explored in much depth, skillfully crossing historical, geographical and disciplinary boundaries. The book is extremely well written; Allan's vivid account of Twitter's CNN moment in reporting on the killing of Osama bin Ladenin Chapter 1 'Accidental Journalism' - reads almost as a thriller and will be remembered as one of the best openings in journalism studies literature so far. The range and the scope of evidence offered is also impressive. In Chapter 2, following on his earlier work on the Lipmann-Dewey debate (Allan 2010), he explores the challenging relationship between the 'journalist as professional observer' and the ordinary citizen in the light of professional elitism and accidental witnesses. The importance of amateur contributions to professional newsmaking is discussed in Chapter 3, and the centrality of witnessing in creating media imagery around the distant other in Chapter 4. The Arab Spring, social media and news are central themes in Chapter 5, while Wikileaks, whistle-blowers and investigative journalism underpin the 
discussion in Chapter 6. 'The Global Village of Images', the reflection on the coverage of the Arab Spring and Libya, positions citizen witnessing and emerging forms of journalism at the forefront of the debate about improving the "quality, depth and rigor of online news-reporting in the public interest' (p.206).

This is an important book that moves the current debate about the future of journalism into a new domain. It turns around the old question of whether journalism would thrive or perish under the pressure of public involvement in news-making by demonstrating how citizen witnessing has a remarkable capacity to enhance both journalism and democratic culture. It is a must-read for journalism scholars, students and practitioners alike.

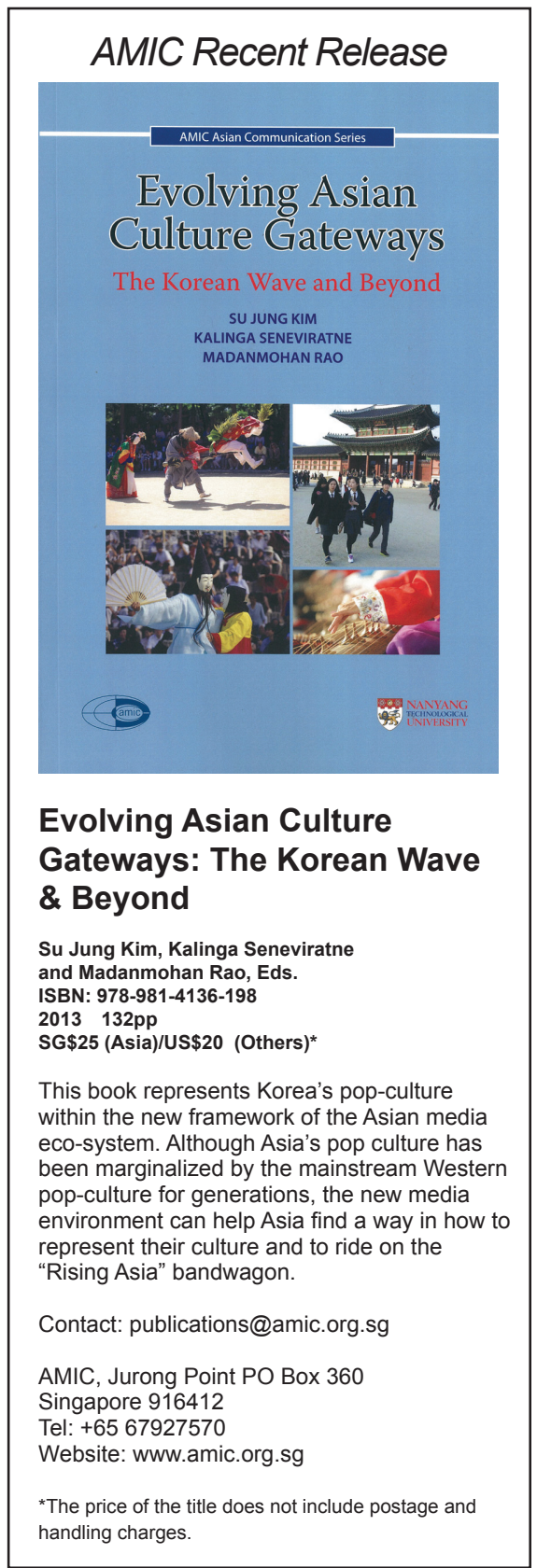

PACIFIC JOURNALISM REVIEW 19 (2) 2013245 